\title{
Prática segura de audiologistas durante a pandemia de SARS-CoV-2 no Brasil
}

\section{Safe practice of audiologists during the SARS-CoV-2 pandemic in Brazil}

\author{
Thales Rafael Correia de Melo Lima' ${ }^{1}$ (D), Silvia de Magalhães Simões² (D), Carlos Kazuo Taguchi (D), \\ Brenda Carla Lima Araújo ${ }^{3}$
}

\section{RESUMO}

A doença de coronavírus (COVID-19) é causada pela síndrome respiratória aguda grave coronavírus 2 (SARS-CoV-2). O vírus é transmitido, principalmente, por gotículas, espirros e aerossóis e pode ser transmitido mesmo entre pacientes assintomáticos, havendo risco de contágio durante os procedimentos do audiologista, que utiliza e reutiliza equipamentos clínicos em uma ampla variedade de pacientes. Este artigo teve como objetivo descrever as etapas que podem ser adotadas pelos audiologistas para diminuir o risco de contaminação cruzada na prática clínica, durante a pandemia de SARS-CoV-2. Recomenda-se, portanto, a esses profissionais, o uso de equipamentos de proteção individual, incluindo respiradores N95, luvas de procedimento, protetores para calçados descartáveis, protetores faciais ou óculos de segurança, gorros e aventais descartáveis, além de seguir, rigorosamente, os protocolos de biossegurança durante os cuidados audiológicos.

Palavras-chave: Infecções por coronavirus; Pandemias; Audiologista; COVID-19; Coronavírus; Fonoaudiologia

\begin{abstract}
Coronavirus disease (COVID-19) is caused by severe acute respiratory syndrome coronavirus 2 (SARS-COV2). This virus is transmitted mainly by droplets, sneezes and aerosols and can be transmitted even among asymptomatic patients, so there is a risk of transmission during the audiologist's procedures which, in addition, use and reuse clinical equipment in a wide variety of patients. This article aims to describe the steps that can be taken by the audiologist in order to decrease the risk of cross-contamination in clinical practice during the SARS-CoV-2 pandemic in Brazil. During the COVID-19 pandemic, audiologists are recommended to use personal protective equipment including N95 respirators, clinical gloves, disposable shoe covers, face shields or safety glasses, hair covers and disposable aprons, in addition to strictly following biosafety protocols during audiological care.
\end{abstract}

Keywords: Coronavirus infections; Pandemics; Audiology; COVID-19; Coronavirus; Speech, Language and Hearing Sciences

Trabalho realizado no Programa de Pós-graduação Profissional em Gestão e Inovação Tecnológica em Saúde, Departamento de Fonoaudiologia, Universidade Federal de Sergipe - UFS - Aracaju (SE), Brasil.

${ }^{1}$ Programa de Pós-graduação Profissional em Gestão e Inovação Tecnológica em Saúde, Universidade Federal de Sergipe - UFS - São Cristóvão (SE), Brasil.

${ }^{2}$ Departamento de Medicina, Universidade Federal de Sergipe - UFS - São Cristóvão (SE), Brasil.

${ }^{3}$ Departamento de Fonoaudiologia, Universidade Federal de Sergipe - UFS - São Cristóvão (SE), Brasil.

Conflito de interesses: Não.

Contribuição dos autores: TRCML participou da idealização do estudo, coleta, análise e interpretação dos dados e redação do artigo; SMS e CKT participaram da redação final do artigo; BCLA participou, na condição de orientadora, da idealização do estudo, análise, interpretação dos dados e redação do artigo.

Financiamento: Nada a declarar.

Autor correspondente: Brenda Carla Lima Araújo. E-mail: brendaaraujo@yahoo.com.br

Recebido: Junho 16, 2020; Aceito: Junho 30, 2020 
Há evidências quanto à transmissão do novo coronavírus de uma pessoa a outra, em ambientes de saúde e entre familiares ${ }^{(1)}$. A síndrome respiratória aguda grave SARS-CoV-2 se propaga, principalmente, através de espirros, gotículas de saliva e aerossóis $^{(2)}$ e pode ser transmitida mesmo entre pacientes assintomáticos ${ }^{(3)}$. Na fase atual da pandemia, todos os pacientes devem ser considerados potencialmente infectados ${ }^{(4)}$. A doença do coronavírus (COVID-19) causada pela síndrome respiratória aguda grave coronavírus 2 (SARS-CoV-2) é uma emergência de saúde global em andamento ${ }^{(5)}$. Desta forma, o nível de precaução recomendado para os audiologistas depende do tipo de procedimento que será realizado, independentemente da comprovação ou suspeita de COVID-19 do paciente.

Neste sentido, muitos audiologistas continuam a prestar assistência a pacientes, mesmo durante a pandemia da COVID-19 e, durante esses procedimentos, há a necessidade de utilizar e reutilizar equipamentos, como espéculos, sondas e fones de ouvido, em muitos pacientes. Tais procedimentos representam um risco de transmissão de SARS-CoV-2 para pacientes, além do alto risco ocupacional para os audiologistas.

Até o momento, não há artigos publicados sobre a evidência da atuação do audiologista durante a pandemia do SARS-CoV-2. Portanto, este artigo teve como objetivo fornecer orientações, baseadas em evidências científicas atuais, relacionadas ao controle de infecções, para que o audiologista tenha maior segurança no atendimento ao paciente durante esta pandemia. Orientações adicionais podem ser necessárias quando as condições do surto da COVID-19 se modificarem, inclusive informações sobre o vírus, sua transmissão e impactos.

Primeiramente, os audiologistas devem priorizar o uso dos equipamentos de proteção individual (EPI). O EPI reduz o risco de transmissão, mas não elimina completamente ${ }^{(6)}$. Portanto, os audiologistas devem ser treinados pela instituição em que estão inseridos sobre quando, como e qual EPI utilizar, além de conhecer diretrizes para procedimentos de descarte, desinfecção e ordem correta de colocação e remoção do EPI, de maneira adequada e segura, para evitar a contaminação.

Estratégias de proteção devem ser implantadas, incluindo medição de temperatura, atendimento com hora marcada e o cuidado para evitar superlotação na circulação de áreas comuns e salas de espera, seja em consultórios ou em regime hospitalar ambulatorial. As evidências atuais apontam que a proximidade e o contato entre indivíduos suscetíveis e pacientes com casos confirmados de COVID-19, (estar, aproximadamente, a 1,8 m de distância, dentro da sala ou na área próxima a uma pessoa infectada) aumenta o risco de contágio de SARS-CoV-2 $2^{(7,8)}$.

As medidas de prevenção e controle de infecção devem ser concretizadas para prevenir ou reduzir, ao máximo, a transmissão de microrganismos durante qualquer assistência à saúde realizada. As seguintes recomendações, baseadas nas evidências atuais, certamente evoluirão, à medida que novos conhecimentos forem gerados:

- Higienizar as mãos com água e sabão, antes e depois de cada atendimento e/ou esfregar as mãos com etanol 70\%, ou isopropanol a $70 \%{ }^{(9)}$, antes e depois dos procedimentos audiológicos. Os audiologistas devem evitar tocar os olhos, nariz ou boca, quando as mãos não estiverem limpas. O SARS-CoV pode ser inativado facilmente com muitos desinfetantes comumente usados ${ }^{(10)}$. A eficácia de alguns desinfetantes contra o coronavírus foi avaliada e os autores concluíram que, em todas as preparações testadas, o SARS-CoV foi inativado abaixo do limite de detecção (fator de redução principalmente $\geq 4$ ). Um estudo apontou que esfregar as mãos com etanol $70 \%$, ou isopropanol $70 \%$ pode ser eficaz contra vírus envelopados, incluindo SARS-CoV ${ }^{(11)}$;

- Os equipamentos de proteção individual (EPI) devem ser utilizados, considerando que muitos pacientes são assintomáticos e, além disso, os testes de diagnóstico não são totalmente confiáveis. De fato, existem cerca de $30 \%$ de resultados falso-negativos com a detecção de SARS-Cov-2, por reverse transcription-polymerase chain reaction (RT-PCR) de $s w a b$ de nasofaringe ${ }^{(12,13)}$. Portanto, devem ser utilizados respiradores N95, máscaras cirúrgicas, luvas de procedimento, protetores faciais, óculos para proteção, toucas, aventais descartáveis e protetores de calçados descartáveis ${ }^{(14)}$. A máscara cirúrgica é um equipamento de proteção individual descartável que produz uma resistência física na cavidade oral e nasal do usuário a prováveis agentes de contaminação no ambiente ${ }^{(15)}$. Os EPI devem ser descartados em sacos apropriados, imediatamente após o uso;

- É importante considerar a limpeza, desinfecção e esterilização de superfícies de equipamentos ou instrumentos não descartáveis, como espéculos, sondas e fones de ouvido, respeitando as recomendações e técnicas estabelecidas pelas diretrizes de biossegurança para fonoaudiólogos, além de uso de EPI apropriado ${ }^{(9)}$. $\mathrm{O}$ alto risco de contaminação no ambiente de avaliação audiológica também deve ser considerado, bem como os consultórios de audiologistas e otorrinolaringologistas, pois, em muitos casos, esses locais são procurados, principalmente, por pacientes com sintomas. Nestes casos, é recomendado o uso de máscaras mais eficientes, como a N95. Até o momento, o que se conhece sobre a sobrevivência do SARS-CoV-2 é que o vírus apresenta mais estabilidade nas superfícies de plástico e aço inoxidável, onde pode ser detectado por até 72 horas, em comparação a 24 horas em papelão e de 40 minutos a 2 horas e 30 minutos em forma de aerossol ${ }^{(16)}$;

- Equipamentos como microfones, utilizados na logoaudiometria, vibradores ósseos e fios nas partes interna e externa das cabinas, devem ser desinfetados com álcool isopropílico. Destaca-se, ainda, a necessidade de uso do protetor descartável individual nas almofadas dos fones supraurais. É importante manter um prazo adequado entre as consultas, para que possa ser realizada a limpeza correta das estruturas do local de atendimento dos audiologistas. As medidas de desinfecção devem ser eficazes e rigorosas em ambientes clínicos e na área pública. $\mathrm{O}$ ambiente clínico deve ser limpo e desinfetado, de acordo com os protocolos estabelecidos para o gerenciamento de limpeza e desinfecção de superfícies médicas, divulgado pela National Health ${ }^{(3)}$. A evidência também sugere que, da mesma forma, os aparelhos devem ser frequentemente limpos e desinfetados, incluindo maçanetas, cadeiras e mesas $^{(3)}$. Sabendo-se que os materiais mais utilizados no revestimento interno das cabinas são espumas das mais variadas formas e modelos, com facilidade para absorção de fungos, bactérias, odores, dentre outros, sendo, portanto, difíceis de higienizar, é importante revestir suas paredes internas com plástico transparente. 
A superfície do revestimento deve ser desinfetada com um papel-toalha embebido em álcool etílico $70 \%$, ou em gel, antes e após o atendimento de cada paciente ${ }^{(17)}$;

- Uma teleconsulta pode ser planejada, caso seja útil e a condição do paciente permitir ${ }^{(4)}$;

- Os brinquedos localizados na área de espera, ou utilizados em exames infantis, também devem ser desinfetados diariamente, pois as crianças podem colocar na boca, resultando em presença de saliva nas superfícies do brinquedo. A evidência indica que o SARS-CoV pode ser transmitido indiretamente, através de contato da mucosa com superfícies infectadas ${ }^{(18)}$. Ou seja, a infecção respiratória aguda pode ser causada pelo contato da mucosa com objetos poluídos pelo vírus, em situações não ocupacionais. Atualmente, a Organização Mundial de Saúde (OMS) recomenda o uso de álcool etílico a $70 \%$ para desinfetar pequenas áreas superficiais e equipamentos reutilizáveis ${ }^{(19)}$.

Ainda não há consenso na literatura sobre alterações auditivas por coronavírus. Por outro lado, um estudo relatou envolvimento do tronco cerebral por infecção do coronavírus. Sendo assim, é possível a ocorrência de um problema neuroauditivo ${ }^{(20,21)}$. Há relatos na literatura sobre dificuldades que os pacientes com deficiência auditiva enfrentam para compreender e se comunicar com a equipe de saúde que usa constantemente equipamentos de proteção individual (EPI) ${ }^{(22)}$, pois a máscara facial, apesar de representar uma aliada no enfrentamento da COVID-19, reduz a transmissão acústica e impede a leitura labial(23).

Por fim, para controlar a disseminação do SARS-CoV-2, é necessário esforço intenso dos profissionais de saúde para enfrentar o desafio atual apresentado pela COVID-19 e ajudar a preparar a população para futuras pandemias. Além das orientações apresentadas neste trabalho, os audiologistas também devem inteirar-se sobre o uso adequado do EPI, consultar as políticas locais do departamento de saúde e revisar, regularmente, as diretrizes de saúde de seus países, que são relevantes para o contexto em que atuam.

\section{REFERÊNCIAS}

1. Chan JFW, Yuan S, Kok KH, To KKW, Chu H, Yang J, et al. A familial cluster of pneumonia associated with the 2019 novel coronavirus indicating person-to-person transmission: a study of a family cluster. Lancet. 2020;395(10223):514-23. http://dx.doi.org/10.1016/S01406736(20)30154-9. PMid:31986261.

2. Lu CW, Liu XF, Jia ZF. 2019-nCoV transmission through the ocular surface must not be ignored. Lancet. 2020;395(10224):e39. http:// dx.doi.org/10.1016/S0140-6736(20)30313-5. PMid:32035510.

3. Li R, Pei S, Chen B, Song Y, Zhang T, Yang W, et al. Substantial undocumented infection facilitates the rapid dissemination of novel coronavirus (SARS-CoV2). Science. 2020;368(6490):489-93. http:// dx.doi.org/10.1126/science.abb3221. PMid:32179701.

4. Mattei A, Amy de la Bretèque B, Crestani S, Crevier-Buchman L, Galant C, Hans S, et al. Guidelines of clinical practice for the management of swallowing disorders and recent dysphonia in the contexte of the COVID-19 pandemic. Eur Ann Otorhinolaryngol Head Neck Dis. 2020;137(3):173-5. http://dx.doi.org/10.1016/j.anorl.2020.04.011.

5. Yuen KS, Ye ZW, Fung SY, Chan CP, Jin DY. SARS-CoV-2 and COVID-19: the most important research questions. Cell Biosci.
2020;10(1):40. http://dx.doi.org/10.1186/s13578-020-00404-4. PMid:32190290.

6. Ağalar C, Öztürk Engin D. Protective measures for COVID-19 for healthcare providers and laboratory personnel. Turk J Med Sci. 2020;50(SI-1):578-84. http://dx.doi.org/10.3906/sag-2004-132. PMid:32299205.

7. Sohrabi C, Alsafi Z, O’Neill N, Khan M, Kerwan A, Al-Jabir A, et al. Corrigendum to "World Health Organization declares Global Emergency: a review of the 2019 Novel Coronavirus (COVID-19)" [Int. J. Surg. 76 (2020) 71-76]. Int J Surg. 2020;77:217. http://dx.doi.org/10.1016/j. ijsu.2020.03.036. PMid:32305321.

8. Asadi S, Bouvier N, Wexler AS, Ristenpart WD. The coronavirus pandemic and aerosols: does COVID-19 transmit via expiratory particles? Aerosol Sci Technol. 2020;54(6):635-8. http://dx.doi.org /10.1080/02786826.2020.1749229. PMid:32308568.

9. CDC: Centers for Disease Control and Prevention. Statement for healthcare personnel on hand hygiene during the response to the International Emergence of COVID-19 [Internet]. Atlanta: CDC; 2020 [citado em 2020 Abr 9]. Disponível em: https://www.cdc.gov/coronavirus/2019-ncov/ hcp/hand-hygiene.html?CDC_AA_refVal=https $\% 3 \mathrm{~A} \% 2 \mathrm{~F} \% 2 \mathrm{Fwww}$. cdc.gov\%2Fcoronavirus\%2F2019-ncov\%2Finfection-control\%2Fhcphand-sanitizer.html

10. Rabenau HF, Kampf G, Cinatl J, Doerr HW. Efficacy of various disinfectants against SARS coronavirus. J Hosp Infect. 2005;61(2):10711. http://dx.doi.org/10.1016/j.jhin.2004.12.023. PMid:15923059.

11. Kampf G. Efficacy of ethanol against viruses in hand disinfection. J Hosp Infect. 2018;98(4):331-8. http://dx.doi.org/10.1016/j.jhin.2017.08.025. PMid:28882643.

12. Wang W, Xu Y, Gao R, Lu R, Han K, Wu G, et al. Detection of SARS-CoV-2 in different types of clinical specimens. JAMA. 2020;323(18):1843-4. http://dx.doi.org/10.1001/jama.2020.3786. PMid:32159775.

13. Ai T, Yang Z, Hou H, Zhan C, Chen C, Lv W, et al. Correlation of chest CT and RT-PCR testing in Coronavirus disease 2019 (COVID-19) in China: a report of 1014 cases. Radiology. 2020;200642. http://dx.doi. org/10.1148/radiol.2020200642. PMid:32101510.

14. Brasil. Conselho Federal de Fonoaudiologia. Resolução CFFa n ${ }^{\circ} 576$, de 19 de junho de 2020. Dispõe sobre os atendimentos ambulatoriais na vigência dos riscos de contágio pelo coronavírus (SARS-CoV-2). Diário Oficial da União [Internet]; Brasília; 22 jun 2020 [citado em 2020 Jun 24]. Disponível em: https://www.fonoaudiologia.org.br/ resolucoes/resolucoes_html/CFFa_N_576_20.htm

15. Ghinai I, McPherson TD, Hunter JC, Kirking HL, Christiansen D, Joshi K, et al. First known person-to-person transmission of severe acute respiratory syndrome coronavirus 2 (SARS-CoV-2) in the USA. Lancet. 2020;395(10230):1137-44. http://dx.doi.org/10.1016/S01406736(20)30607-3. PMid:32178768.

16. Van Doremalen N, Bushmaker T, Morris DH, Holbrook MG, Gamble A, Williamson BN, et al. Aerosol and surface stability of SARS-CoV-2 as compared with SARS-CoV-1. N Engl J Med. 2020;382(16):1564-7. http://dx.doi.org/10.1056/NEJMc2004973. PMid:32182409.

17. CFFa: Conselho Federal de Fonoaudiologia. Nota orientativa: higienização das cabinas acústicas [Internet]. Brasília: CFFa; 2020 [citado em 2020 Jun 24]. Disponível em: https://www.fonoaudiologia.org.br/cffa/index. php/2020/04/nota-orientativa-higienizacao-das-cabinas-acusticas/

18. Peiris JSM, Yuen KY, Osterhaus ADME, Stöhr K. The severe acute respiratory syndrome. N Engl J Med. 2003;349(25):2431-41. http:// dx.doi.org/10.1056/NEJMra032498. PMid:14681510.

19. WHO: World Health Organization. Water, sanitation, hygiene and waste management for the COVID-19 virus. Genebra: WHO; 2020. p. 1-9. 
20. Sriwijitalai W, Wiwanitkit V. Hearing loss and COVID-19: a note. Am J Otolaryngol. 2020;41(3):102473. http://dx.doi.org/10.1016/j. amjoto.2020.102473. PMid:32276732.

21. Wege H, Watanabe R, ter Meulen V. Relapsing subacute demyelinating encephalomyelitis in rats during the course of coronavirus JHM infection. J Neuroimmunol. 1984;6(5):325-36. http://dx.doi.org/10.1016/01655728(84)90022-5. PMid:6086712.
22. Trecca EMC, Gelardi M, Cassano M. COVID-19 and hearing difficulties. Am J Otolaryngol. 2020;41(4):102496. http://dx.doi.org/10.1016/j. amjoto.2020.102496. PMid:32327217.

23. CNN. For the deaf or hard of hearing, face masks pose new challenge [Internet]. 2020 [citado em 2020 Jun 24]. Disponível em: https:// edition.cnn.com/2020/04/02/opinions/deaf-hard-of-hearing-facemasks-brooks/index.html 